\title{
Relationship status: libraries and linked data in Europe
}

\author{
Dr Diane Rasmussen Pennington MS PhD PgDip FHEA FRSA \\ Lecturer in Information Science \& Course Director, University of Strathclyde \\ @infogamerist \\ diane.pennington@strath.ac.uk
}

\author{
Ms Laura Cagnazzo MA MSc \\ @LauraFCagnazzo \\ laurafcagnazzo@outlook.com
}

\section{Introduction}

Libraries shared metadata long before the advent of the Internet by utilising standards such as MARC and AACR to enable interoperability (Tallerås, 2013). A difficulty with their use in the networked environment has been the inability to exchange data at scale, due to the diversity of descriptive standards and schemas adopted as well as the diversity of languages in use (Breeding et al., 2016). Linked data offers libraries the means for enabling interoperability, improving data management, and enhancing the amount and quality of information available to more people (Byrne \& Goddard, 2010). It can enhance discoverability of library data, eventually helping libraries realise their dream of appearing within those coveted first ten results when searching the open Web. With linked data, people lacking knowledge of library jargon and metadata standards can finally benefit from the rich information stored in libraries' catalogues and other online resources (Rasmussen Pennington, 2016).

We are approaching the end of cataloguing records containing siloed library-provided data, and moving towards enriched data coming from various resources. This requires library data to be structurally flexible and applicable to multiple online contexts (Coyle, 2009). Essentially, "We are moving from cataloguing to catalinking" (Wallis, 2013, slide 19).

This presentation will include the convergence of two related studies: linked data implementation across European national libraries (Cagnazzo, 2017), and linked data awareness and use among Scottish libraries (Rasmussen Pennington, 2017). Whilst the first offers a more global view, the latter provides a targeted lens on one country.

\section{Objectives}

We will present our results highlighting stated reasons for linked data adoption or non-adoption in Scottish libraries and European national libraries, including perceptions of the benefits and challenges surrounding adoption. We will offer a comprehensive picture of how European national libraries and Scottish institutions perceive the call of the Semantic Web and how they are responding to it. We will present use cases to exemplify the different purposes linked data can serve, identify technical difficulties and outline solutions adopted to overcome them. We will then suggest recommendations for institutions wanting to embrace the Semantic Web, including how to overcome common issues faced in implementation.

The research questions addressed were as follows:

- What are librarians' understandings of the concepts "linked data" and "Semantic Web"?

- What are the perceived benefits of library linked data implementation?

- What are the reasons behind libraries' decisions to implement or not implement linked data?

- What are the barriers to linked data adoption?

- What are the challenges encountered by libraries before and during linked data implementation? 


\section{Methodology}

A qualitative case study approach provided an in-depth analysis of a few settings. To answer our research questions comprehensively, we utilised multiple data gathering techniques:

- Literature review: started to investigate the status of linked data implementation and use across European national libraries.

- Semi-structured interviews ( $\mathrm{n}=15)$ : interviewed information professionals working with linked data or metadata in European national libraries.

- Online resources analysis $(n=26)$ : used browser extensions able to recognise Semantic Web structures (such as Semantic Radar) identify whether non-participating European national libraries' websites had implemented linked data.

- Survey ( $\mathrm{n}=113)$ : Public, academic, school and national librarians in Scotland participated in an online survey aimed at understanding the awareness, perceptions and adoption of library linked data.

- We analysed these data through constant comparative analysis, an analysis approach used on disparate resources (Onwuegbuzie et al., 2012).

\section{Results}

A strong need to increase Semantic Web awareness and its potential within libraries emerged. Librarians are uncertain about the meanings of "Semantic Web" and "linked data". Scotland exemplifies the obstacles that most institutions experience with Semantic Web implementation.

Professionals expressed viewpoints on perceived and experienced benefits and challenges of linked data implementation at their institutions. The most common barriers hindering linked data implementation were lack of expertise, lack of time, lack of staff, licensing constraints and difficulties in obtaining management buy-in.

The online resources analysis afforded the identification of RDF structures on the National Library of Ukraine and the National Parliamentary Library of Georgia's websites, as well as implementation efforts at the National Library of Switzerland.

\section{Conclusions}

A minority of participating institutions ( $n=9$ national libraries; $n=8$ Scottish libraries) have applied linked data. Some projects demonstrated the advantages of augmenting the visibility and discoverability of library data, supporting interoperability, and overcoming obstacles such as linguistic barriers. However, several issues remain unsolved, such as licensing constraints and reuse vs creation of ontologies. Even where open data policies are government-mandated, libraries expressed a need for successful implementation examples for management buy-in. Collaboration among institutions is key to enable further Semantic Web development.

\section{References}

Breeding, M., Kroeger, A. and Sandy, H.M. (2016) 'Sharing metadata across discovery systems', in Spiteri, L. (ed.) Managing metadata in web-scale discovery systems. London: Facet Publishing, pp.17-55.

Byrne, G. and Goddard, L. (2010) 'The strongest link: Libraries and Linked Data'. D-Lib Magazine, 16(11/12). Available at: http://www.dlib.org/dlib/november10/byrne/11byrne.html (Accessed: 23 September 2017).

Cagnazzo, L. (2017) Linked Data: Implementation, Use, and Perceptions across European National Libraries. MSc Dissertation. University of Strathclyde. 
Coyle, K. (2009) 'Metadata mix \& match'. Information Standards Quarterly, 21(1), pp. 9-11. Available at: http://www.kcoyle.net/isqv21no1.pdf (Accessed: 23 September 2017).

Onwuegbuzie, A.J., Leech, N.L. and Collins, K.M. (2012) 'Qualitative analysis techniques for the review of the literature'. The Qualitative Report, 17(28), pp.1-28. Available at: http://nsuworks.nova.edu/tqr/vol17/iss28/2 (Accessed: 12 October 2017).

Rasmussen Pennington, D. (2016) 'Demystifying Linked Data: Are you ready for what's next?' CILIP Update, July-August, pp.34-36.

Rasmussen Pennington, D. (2017) 'Linked data: Opening Scotland's library content to the world'. [PowerPoint presentation]. CILIPS Conference 2017. Available at: https://www.slideshare.net/CILIPScotland/linked-data-opening-scotlands-library-content-to-the-world (Accessed: 12 October 2017).

Tallerås, K. (2013) 'From many records to one graph: Heterogeneity conflicts in the linked data restructuring cycle'. Information Research, 18 (3). Available at: http://www.informationr.net/ir/183/colis/paperC18.html\#.WUEwnZB95dg (Accessed: 16 September 2017).

Wallis, R. (2013) 'Linked Data for libraries: Great progress, but what is the benefit?' Semantic Web in Libraries (SWIB13) Conference, Hamburg, Germany. 26 November 2013. Available at: https://www.slideshare.net/rjw/linked-data-for-libraries-great-progress-but-what-is-the-benefit (Accessed 07 September 2017). 